\title{
ASPECTOS DA GESTÃO ESCOLAR E DA TRÍADE ENSINO, PESQUISA E EXTENSÃO
}

\author{
ASPECTOS DE LA GESTIÓN ESCOLAR Y DE LA TRÍADA EDUCACIÓN, \\ INVESTIGACIÓN Y EXTENSIÓN
}

\author{
ASPECTS OF SCHOOL MANAGEMENT AND THE TRIAD TEACHING, RESEARCH \\ AND EXTENSION
}

Jaeder Araujo MONTEIRO1

RESUMO: Este artigo objetivou descrever de maneira concisa acerca da Gestão escolar contemporânea e suas duas divisões, no caso a Gestão pedagógica e a Gestão administrativa. Bem como, caracterizar o Ensino superior, a tríade Ensino, Pesquisa e Extensão e as personagens que estão envolvidas no processo de "esforço coletivo" voltado às práticas da Educação de qualidade. A fundamentação teórica desta pesquisa tem por alicerce estudos a respeito dos temas supracitados. Através de uma pesquisa bibliográfica foram obtidos elementos para a constituição do referencial teórico. A construção em questão, possibilitará a ampliação da discussão sobre os temas abordados, assim como, sobre as práticas desenvolvidas e direcionadas a alcançar de um modelo de Gestão escolar que supra as necessidades profissionais e sociais dos indivíduos.

PALAVRAS-CHAVE: Gestão escolar. Ensino, pesquisa e extensão. Esforço coletivo.

RESUMEN: Este artículo tuvo como objetivo describir de manera concisa la Gestión escolar contemporánea y sus dos divisiones, en este caso la Gestión pedagógica y la Gestión administrativa. Además de caracterizar la educación superior, la tríada Enseñanza, Investigación y Extensión y los personajes que participan en el proceso de "esfuerzo colectivo" dirigido a prácticas educativas de calidad. La base teórica de esta investigación se basa en estudios sobre los temas antes mencionados. A través de la investigación bibliográfica, se obtuvieron elementos para la constitución del marco teórico. La construcción en cuestión permitirá ampliar la discusión sobre los temas tratados, así como en las prácticas desarrolladas y dirigidas a lograr un modelo de Gestión escolar que satisfaga las necesidades profesionales y sociales de las personas.

PALABRAS CLAVE: Gestión escolar. Docencia, investigación y extensión. Esfuerzo colectivo.

ABSTRACT: This article aimed to concisely describe contemporary school Management and its two divisions, in this case pedagogical Management and administrative Management. As well as characterizing higher education, the triad Teaching, Research and Extension and the characters who are involved in the "collective effort" process aimed at quality education

1 Universidade Tecnológica Intercontinental (UTIC), Assunção - Paraguai. Doutorando em Ciências da Educação. ORCID: https://orcid.org/0000-0001-7575-2256. E-mail: montjae@gmail.com

RPGE- Revista on line de Política e Gestão Educacional, Araraquara, v. 25, n. 1, p. 52-67, jan./abr. 2021. e-ISSN:1519-9029 DOI: https://doi.org/10.22633/rpge.v25i1.13913 
practices. The theoretical basis of this research is supported on studies on the themes that were mentioned before. Elements for the constitution of the theoretical reference were obtained through bibliographic research. The construction in question will allow the expansion of the discussion on the topics covered and also about the practices developed and directed to achieving a school Management model that meets the professional and social needs of individuals.

KEYWORDS: School management. Teaching, research and extension. Collective effort.

\section{Introdução}

Sabe-se que o termo Gestão escolar faz referência ao ato de gerir uma instituição escolar, uma espécie de termo evoluído dos termos Administração, Administração escolar, conforme mencionam vários autores. No decorrer dos tempos, essa evolução ocorreu não apenas na nomenclatura, mas também de forma prática e usual, uma vez que, a principal diferença dos termos, que também são considerados sinônimos, encontra-se na forma fria e romântica de sua aplicação. Em outras palavras, apesar de todos os termos na prática utilizarem os princípios básicos: planejar, dirigir, controlar e executar, o único que tem o viés voltado em forma ao contingente humano é a chamada Gestão escolar. A Administração e Administração escolar são reconhecidas, até o presente momento, como mais frias e capitalistas, mesmo quando eram aplicadas em instituições educacionais.

Sander (2007) menciona que o caráter da Gestão escolar no Brasil, em referência aos primeiros estudos, circundava o entendimento e utilizava o termo Administração escolar.

Nota-se que os termos evoluíram, como também houve a evolução da mentalidade, das práticas e ações que os envolvem. Na atualidade, a ideia de gerir ou administrar de forma fria não é bem aceita. O termo correto a ser mencionado é Gestão, ou seja, gerir de forma ampliada, globalizada a instituição e não apenas atentar para a execução correta do planejamento, mas de forma concomitante, importar-se com os anseios e necessidades do seu contingente humano.

Com isso, serão apresentados conceitos e assuntos relevantes que envolvem o tema principal desta construção, ou seja, ocorrerão nos tópicos seguintes abordagens com o intuito de caracterizar aspectos relativos a Educação, Ensino superior, Legislação, Gestão, Gestão Escolar e a tríade Ensino, Pesquisa e Extensão que, por sua vez, contribuem para o bom desenvolvimento da Gestão Escolar desenvolvida nas instituições superiores de Ensino onde é trabalhada a tríade Ensino, Pesquisa e Extensão. 


\section{Educação, ensino superior e legislação}

O ambiente escolar não é algo indiferente à sociedade. Muito pelo contrário, está ligado e inserido na sociedade e tem extrema relevância em seus acontecimentos.

Santos (2008, p. 62) menciona que a sociedade "é um organismo vivo, que reflete, aceita as modificações que ocorrem na sociedade e na Gestão do poder, e também reage ou se acomoda a elas". Percebe-se a extrema ligação entre escola e sociedade por meio da influência recíproca, ou seja, a sociedade tem o poder de influenciar as atividades e Ensino ofertados pela escola, bem como a escola tem poder de influenciar a sociedade através de suas ações.

Ao mesmo tempo que se ensina, também se aprende. Através de um mero gesto ou situação também podemos aprender e ensinar. O papel da Educação e, em consequência, o papel do educador não é apenas ensinar de forma literal, ou seja, reproduzir o que está contido nos livros. Mas sim fazer com que os alunos se tornem críticos pensantes, questionadores que sejam capazes de refletir e chegar as suas próprias conclusões mediante o conteúdo absorvido e vivências de mundo, segundo assinala Freire (1996).

Entende-se a relevância da Educação para a diminuição das desigualdades e para a elevação do estímulo ao crescimento de um país, o que, a nosso modo de pensar, não é uma mera questão de concordância de opiniões. Nesse enquadramento, a escola, representada pela Educação superior, se apresenta de maneira essencial. Pois, é através da formação superior que são identificados os maiores e melhores salários do mercado.

Sendo assim, é justo mencionar a ideia de Silva (2007) em referência a importante história que envolve a origem da universidade em nosso país:

O rei D. João VI, ao utilizar como base o paradigma político de Portugal, não fundou nenhuma universidade no Brasil por receio que a Colônia viesse a se tornar independente. Bem como não autorizou a formação de oficiais engenheiros e médicos com base no nível de Ensino médio, existente no Brasil da época (SILVA, 2007).

Sabe-se que, ao oposto de vários outros países, onde o Ensino superior teve origem através das universidades, no Brasil este tipo de Ensino emergiu por meio das faculdades isoladas, onde primordialmente era imposta a formação profissional.

Moacyr (1937) relata, a história da criação da universidade no Brasil demonstra em seu início certa resistência, tanto por parte de Portugal, confirmando assim o seu tipo de política de colonização, quanto também por parte de brasileiros, que não acreditavam na ideia da criação de uma instituição desse gênero na Colônia. $\mathrm{O}$ entendimento dos brasileiros, na 
época, era que tal criação não se justificava e o mais correto seria que a elite se deslocasse a Europa para cursar estudos de nível superior.

A Educação superior brasileira é composta por um sortido grupo de instituições públicas e privadas, que englobam vários tipos de cursos e programas, integrando diversos níveis de Ensino, desde a graduação até a pós-graduação lato e stricto sensu. O atual regime de funcionamento de tais instituições tem por base a Constituição Federal do Brasil de 1988, a Lei de diretrizes e bases da Educação nacional - LDBEN 9.394 de 1996 e um considerável conjunto de decretos, regulamentos e portarias complementares (NEVES, 2002).

Nota-se, na atualidade, que emergem jovens perspectivas para universidade brasileira no século XXI. Tais possibilidades carecem atender às necessidades socioculturais dos cidadãos, por meio do desenvolvimento do conhecimento, da informação e, sobretudo, da Educação.

Fávero (1997, p. 13) menciona que é necessário

[...] analisar as funções da Universidade na sociedade, é necessário determinar não só os objetivos pedagógicos, mas também os objetivos sociais, políticos e culturais. É fundamental definir o grau de participação de cada uma das instâncias que constitui a organização universitária, bem como o grau de autonomia com que se pretende atingir.

Concorda-se que, por muito tempo, as instituições de Ensino superior estiveram focadas na formação de profissionais que suprissem as demandas locais de suas pertinências sociais.

Cavalcante (2000) explana a consolidação da Pesquisa universitária de forma acentuada nas instituições públicas; a qualificação dos corpos docentes e de Extensão universitária são atividades de notória relevância para a integração das instituições de Ensino superior com a comunidade e o setor empresarial.

O Ensino superior, contemporaneamente, evoluiu e se apresenta através da tríade Ensino, Pesquisa e Extensão. Percebe-se que tal evolução ocorreu e ocorrerá através do posicionamento e das decisões firmes tomadas pelos responsáveis pela Gestão escolar. Especificamente considerando que o Gestor escolar é a personagem principal da Gestão escolar e, através das ações deste, serão moldados e aperfeiçoados o planejamento, os procedimentos e as pessoas envolvidas no alcance do objetivo pretendido. Sendo assim, será abordado o ponto que demonstra a importância do Gestor escolar juntamente da Gestão escolar desenvolvida. 


\section{Gestão escolar e o gestor escolar}

Neste subtópico serão evidenciados, de forma sucinta, os conceitos que envolvem a Gestão escolar e a atuação do Gestor escolar, bem como sua atuação. Entende-se que, os termos Administração, Administração escolar e Gestão escolar possuem significados semelhantes. E, porque não dizer, são sinônimos ou termos que evoluíram no sentido prático.

Martins (1999, p. 02), comenta que,

Administração escolar supõe uma filosofia e uma política diretoras preestabelecidas: consiste no complexo de processos criadores de condições adequadas às atividades dos grupos que operam em divisão de trabalho; visa à unidade e à economia de ação, bem como ao progresso de empreendimento. $\mathrm{O}$ complexo de processos engloba as atividades específicas - Planejamento, organização, assistência à execução (gerência), avaliação de resultados (medidas), prestação de contas (relatório) e se aplica a todos os setores da empresa: pessoal, material, serviços e financiamento.

Santos (1996) relata a analogia existente entre os objetivos básicos que envolvem os termos Administração, Administração escolar e Gestão escolar: planejar, organizar, dirigir e controlar os serviços necessários para o bom funcionamento tanto das empresas, quanto das instituições de Ensino.

Observa-se que a principal "diferença" entre os sinônimos Administração, Administração escolar e Gestão escolar, está ligada à forma capitalista e humanizada com que se apresentam. Administração, em sua forma mais pura, é utilizada pelas organizações voltadas ao lucro, ou seja, direcionadas ao capitalismo. A Administração escolar apesar de ser voltada para a formação educacional de indivíduos e não ao lucro, por um longo tempo, foi entendida e julgada como de caráter frio, por utilizar como base os princípios básicos da Administração (CHIAVENATO, 2003). Já o termo Gestão escolar evoluiu mediante a necessidade de humanização quanto a gerir uma instituição de Ensino. Mesmo utilizando os princípios básicos da Administração e da Administração escolar, seu foco é firmar uma Gestão democrática, participativa e humanizadora aos indivíduos em formação e aos Colaboradores que a efetivam, mediante um viés voltado a atender ao campo educacional (CHIAVENATO, 2003).

Mudanças atingem o sistema educacional, exigindo-se dele a adequação aos interesses do mercado e investimentos na formação de profissionais mais preparados para as modificações do processo de produção. Com efeito, tais modificações afetam a organização do trabalho nas empresas e o perfil do trabalhador necessário para novas formas de produção e, em consequência, os conhecimentos, habilidades e atitudes necessárias à qualificação profissional. As incessantes modificações profissionais tecnológicas afetam 
os postos de trabalho e as competências profissionais, de modo que as pessoas precisam estar preparadas para mudar de profissão algumas vezes na sua vida (LIBÂNEO, 2008, p. 47).

Compreende-se que a Gestão escolar do Ensino superior precisa atentar para a efetivação de ações conjuntas entre a área pedagógica e administrativa. Afinal, uma complementa a outra. É difícil imaginar que uma instituição de Ensino superior alcance seus propósitos com excelência sem o devido alinhamento entre as duas áreas que compõem a Gestão escolar.

Com base na literatura pesquisada, e por visão prática do assunto desenvolvido neste estudo, pode-se descrever algumas funções ou também denominá-las pelas nomenclaturas atividades/ações desempenhadas pelas áreas pedagógica e administrativa que compõem a Gestão escolar:

O caráter pedagógico da ação educativa consiste precisamente na formulação de objetivos sócio-políticos e educativos e na criação de formas de viabilização organizativa e metodológica da Educação (tais como a seleção e organização dos conteúdos e métodos, a organização do Ensino, a organização do trabalho escolar), tendo em vista dar uma direção consciente e planejada ao processo educacional. O processo educativo, portanto, pela sua natureza, inclui o conceito de direção. Sua adequada estruturação e seu ótimo funcionamento constituem fatores essenciais para se atingir eficazmente os objetivos de formação. Ou seja, o trabalho escolar implica uma direção (LIBẤNEO, 2001, p. 114-115).

Entende-se que, algumas funções pedagógicas básicas são: Organizar calendário letivo; Planejar o período letivo; Organizar reuniões voltadas ao planejamento escolar; Coordenar reuniões e decisões voltadas aos rendimentos dos discente; Orientação pedagógica aos docentes; Zelar pela disciplina dos discentes no ambiente escolar; Realizar a aproximação com as famílias dos discentes.

Já as funções administrativas, de acordo com Chiavenato (2003, p. 94),

São as funções relacionadas com a integração das outras cinco funções (técnicas, comerciais, financeiras, de segurança, contábeis e administrativas). Para Fayol, as funções administrativas englobam: prever, organizar, comandar, controlar e coordenar. Atualmente, as funções administrativas envolvem: planejamento, organização, direção e controle. Em seu conjunto, as funções administrativas formam o processo administrativo.

Percebe-se que a atuação atenta do Diretor escolar é de grande importância, ou seja, esteja sempre presente e tenha conhecimento de todas as decisões e ações posteriores ao planejamento da Gestão escolar consolidado. Será por meio de seus parceiros (Diretores, Coordenadores e demais Colaboradores) que tais necessidades de execução serão repassadas 
e, assim, realizadas as funções e tarefas destinadas ao alcance do objetivo-fim da instituição escolar.

\begin{abstract}
Os gestores escolares, constituídos em uma equipe de gestão, são os profissionais responsáveis pela organização e orientação administrativa e pedagógica da escola, da qual resulta a formação da cultura e ambiente escolar, que devem ser mobilizadores e estimuladores do desenvolvimento, da construção do conhecimento e da aprendizagem orientada para a cidadania competente. Para tanto, cabe-lhes promover a abertura da escola e de seus profissionais para os bens culturais da sociedade e para sua comunidade. Sobretudo devem zelar pela constituição de uma cultura escolar proativa e empreendedora capaz de assumir com autonomia a resolução e o encaminhamento adequado de suas problemáticas cotidianas, utilizando-as como circunstâncias de desenvolvimento e aprendizagem profissional (LÜCK, 2009, p. 22).
\end{abstract}

Compreende-se que, um Gestor pode trabalhar em variadas esferas e campos e, dependendo de sua escolha, não atuará apenas como um "mero" administrador. Esse caso encaixa-se de forma perfeita no assunto Gestão escolar. Por meio da atuação sólida desse profissional muitos indivíduos serão beneficiados pois, através dele, surgirão novas possibilidades de transformações profissionais e sociais, uma vez que o verdadeiro papel do Gestor é atuar como um articulador. Em outras palavras, seu olhar estará voltado ao equilíbrio entre a valorização do contingente humano e a efetivação de procedimentos. Mediante as responsabilidades que envolvem a função de Gestor, quanto à Gestão escolar desenvolvida, é justo destacar a importância do planejamento e das ações desenvolvidas e articuladas em virtude da tríade Ensino, Pesquisa e Extensão, mediante sua inseparabilidade ou indissociabilidade, como definida por diversos autores.

\title{
A tríade Ensino, Pesquisa e Extensão do Ensino superior e sua indissociabilidade
}

Sabe-se que, a universidade foi originada com a intenção da criação de um ambiente onde o conhecimento fosse construído e, em consequência, somasse a função formativa de profissionais. E tem como pilares a serem trabalhados o Ensino, a Pesquisa e a Extensão, que são denominados de tríade.

O Ensino representa as atividades ligadas ao aprendizado dos alunos. Em específico, atividades como: período de aulas ministradas dentro e fora de sala de aula (aula de campo), laboratórios, monitoria, seminários, palestras etc.

Nota-se na atualidade que, as finalidades que envolvem o Ensino superior, também chamado de educação superior pela Lei 9394/96, são bastante abrangentes e visam o 
aperfeiçoamento. Sendo assim, é cabível mencionar trechos que envolvem o contexto que culminou no surgimento da educação superior no Brasil.

Segundo Rossato (2006, p. 22):

a questão do ensino superior brasileiro deve ser situada dentro do processo em que foi feita a escolarização do país. Tal escolarização foi constituída com uma dupla finalidade: a exploração comercial e a realização da cruzada Católico-cristã, no espírito da Contra-Reforma. Em seu início, o ensino superior brasileiro teve um caráter colonialista, dependente, tardio, classista e desvinculado da realidade nacional. A sociedade colonial era arcaica, de cultura oral, fundada na escravidão, no patriarcado rural e na burocracia colonial. Nessa sociedade a educação era predominantemente eclesiástica e destinada à manutenção dos privilégios da ordem social rígida e fechada.

Percebe-se que, no princípio do século XX, o Ensino superior no Brasil inicia sua jornada, apresentando-se de forma peculiar e, com isso, auferindo maior atenção por parte das autoridades e por boa parte da sociedade. Por que isso ocorre? O que isso implica?

Mediante esse novo cenário,

a concepção de universidade que ganhou corpo na década de 20 e o seu surgimento no início da década de 1930 foram o verdadeiro marco do início da universidade no Brasil. Esse marco inicial deveu-se a um contexto em que a universidade já tinha condições de aceitação e constituía uma demanda social. Dentro do espírito da inquietação reinante em 1920, três fatos foram decisivos para a organização da universidade na década de 1930: o inquérito sobre instrução pública realizado em São Marcos em 1926, o Estatuto das Universidades Brasileiras de 1931 e o Manifesto dos Pioneiros da Educação Nova de 1932 (ROSSATO, 2006, p. 19).

A Pesquisa, que também recebe a nomenclatura Pesquisa científica, abrange ações e práticas produzidas com o intuito de incentivar atividades de Pesquisa no ambiente universitário. Tais ações e práticas de uma forma geral acontecem mediante produção de monografias, no trabalho de conclusão de curso - TCC's ou através de iniciação científica.

Concorda-se que, a Pesquisa é de forma prática o emprego de uma gama de processos e métodos de investigação aplicados por pesquisadores para o desenvolvimento de um estudo.

Lakatos e Marconi (1990, p. 15) esclarecem que a palavra pesquisar é percebida como o ato de

averiguar algo de forma minuciosa, é "investigar", bem como o entendimento do termo investigação não é unívoco, pois há várias definições sobre o termo nos diferentes campos de conhecimento. Contudo, o ponto de partida da Pesquisa reside no problema que deverá se definir, avaliar, analisar uma solução para depois ser tentada uma solução. 
A Extensão é um dos alicerces que sustenta a prática da universidade no Ensino superior. A Extensão ou Extensão Universitária é um relevante complemento ao Ensino e à Pesquisa, detendo poder de gerar interação entre instituição de Ensino e a comunidade que a cerca.

Em caráter oficial, a Extensão foi reconhecida como parte integrante da tríade Ensino, Pesquisa e Extensão, que formam a Educação superior no Brasil, por intervenção da Constituição federal do ano de 1988, em específico pelo artigo $n^{0}$ 207, "as Universidades gozam de autonomia didático-científica, administrativa e de Gestão financeira e patrimonial, e obedecerão ao princípio de indissociabilidade entre Ensino, Pesquisa e Extensão" (BRASIL, 1988).

A Extensão Universitária é o que estabelece, através do diálogo, a aproximação e entendimento entre universidade e sociedade, com a intenção da produção de conhecimentos e da interlocução das atividades acadêmicas referentes ao Ensino e a Pesquisa, por meio de processos formativos.

Conforme Soares (2007, p. 2), o desafio da Extensão universitária é “a defesa das políticas públicas, participando na formulação, acompanhamento e avaliação dessas políticas em todos os âmbitos da federação e setores de atuação".

Corrobora-se com a ideia de que a Extensão tem importante papel quanto atuação fora dos muros da instituição de Ensino. A sala de aula foi redefinida e reconhecida como algo que abrange diferenciados espaços, mediante ideia da Política Nacional de Extensão universitária (FORPROEX, 2009, p. 18):

[...] dentro e fora da Universidade, em que se apreende e se (re)constrói o processo histórico-social em suas múltiplas determinações e facetas. $\mathrm{O}$ eixo pedagógico clássico 'estudante - professor' é substituído pelo eixo 'estudante - professor - comunidade'.

Ensino e Pesquisa desde o primeiro Estatuto das universidades, a partir da Reforma Francisco Campos, no ano de 1931, já se apresentavam como funções universitárias. É notória a finalidade do Ensino superior em promover e estimular o nível cultural e a investigação científica.

O significado do termo indissociabilidade, segundo o dicionário online Dicio:

Substantivo feminino. Característica ou particularidade do que é indissociável, inseparável; que não se dissocia; que não pode ser separado nem desunido. Etimologia (origem da Palavra indissociabilidade). Indissociável - vel + bili + dade (DICIO, 2020). 
O termo indissociabilidade não é de uso exclusivo da tríade Ensino, Pesquisa e Extensão, uma vez que é mencionado em outros temas como: indissociabilidade entre teoria e prática; indissociabilidade entre educar e cuidar; indissociabilidade entre atenção e Gestão, entre outros. Enfim, como já mencionado: indissociabilidade é a característica que define a atuação, trabalho ou execução conjunta.

Rays (2003, p. 73) declara a indissociabilidade como "um processo multifacetado de relações e de correlações que busca a unidade da teoria e da prática". Nota-se que, o entendimento a respeito da indissociabilidade existente entre o Ensino, a Pesquisa e a Extensão, não estão limitadas a algo conceitual ou legislativo, mas sim a assuntos de caráter paradigmático, epistemológico e político-pedagógico.

A biografia da universidade brasileira discorre que a indissociabilidade das atividades de Ensino, Pesquisa e Extensão tomaram destaque por volta dos anos 60, com a estruturação dos movimentos estudantis e pela reorganização dos movimentos sociais dos anos 70, firmando-se como propositura na reforma da Educação e parte do processo de redemocratização do Brasil, nos anos 80. A indissociabilidade entre o Ensino, a Pesquisa e a Extensão solidificou-se como bandeira de luta do movimento docente do Ensino superior, com apoio de alunos e de setores progressistas da sociedade civil organizada, ligando-se a oração em defesa da liberdade acadêmica e autogestão (MACIEL, 2010).

Nota-se que, ao estipular que as instituições universitárias seguissem o caminho junto ao princípio de indissociabilidade, a Constituição federal brasileira de 1988 confere ao fazer universitário a ideia que elimina as relações duais entre as três funções.

Moita e Andrade (2009, p. 269) assim explicam os efeitos da fragmentação:

[...] a articulação entre o Ensino e a Extensão aponta para uma formação que se preocupa com os problemas da sociedade contemporânea, mas carece da Pesquisa, responsável pela produção do conhecimento científico. Por sua vez, se associados o Ensino e a Pesquisa, ganha-se terreno em frentes como a tecnologia, por exemplo, mas se incorre no risco de perder a compreensão ético-político-social conferida quando se pensa no destinatário final desse saber científico (a sociedade). Enfim, quando a (com frequência esquecida) articulação entre extensão e Pesquisa exclui o Ensino, perde-se a dimensão formativa que dá sentido à universidade.

Percebe-se que a indissociabilidade da tríade Ensino, Pesquisa e Extensão direciona a prática da produção universitária de qualidade. Nas palavras de Moita e Andrade (2009, p. 72), seria "um catalisador pluriversitário" que possibilita a discussão de ideias entre a universidade e a sociedade. 
A Extensão universitária, através da interferência de caráter social, viabiliza benefícios à comunidade, acarretando mudanças à vida dos indivíduos, estreitando a relação entre a universidade e a comunidade. Sem contar que propiciará aos alunos a chance de uma formação voltada a cidadania (FORPROEX, 2009).

A Lei de diretrizes e bases - LDB 9394/96 -, em seu artigo de número 43, inciso VI, instaura que um dos mais importantes propósitos da Educação superior é: "promover a Extensão, aberta à participação população, visando à difusão das conquistas e benefícios resultantes da criação cultural e da pesquisa científica e tecnológica geradas na instituição".

Corrobora-se que, mediante tal visão, é possível compreender a indissociabilidade como princípio qualificado a transformar o aluno em principal sujeito da formação profissional almejada. Com isso, este pode atinjir o nível de competência satisfatório para executar sua formação técnica, crítica e cidadã, seguro de seus deveres e direitos perante a edificação de uma sociedade justa e igualitária.

Com base no conceito que circunda a indissociabilidade da tríade Ensino, Pesquisa e Extensão, emerge o pensamento de esforço coletivo necessário para que o planejamento e as ações que envolvem sua efetivação ocorram de forma satisfatória.

\section{O esforço coletivo necessário à tríade ensino, pesquisa e extensão do ensino superior}

Como mencionado decorrer desta pesquisa, a tríade Ensino, Pesquisa e Extensão, dentro da indissociabilidade descrita e manifesta por diversos autores e também pelas leis brasileiras que estabelecem o Ensino superior, tem por objetivo fortalecer as atividades desenvolvidas no meio universitário, gerando profissionais e cidadãos críticos.

Para que o sucesso seja alcançado será necessário mais que a atenção às práticas voltadas para a tríade Ensino, Pesquisa e Extensão, uma vez que toda instituição de Ensino requer organização global para a obtenção dos objetivos.

Rodrigues (2011, p. 51) expõe seu olhar quanto a qualidade do Ensino:

[...] está vinculada à satisfação e à motivação, é indicada por uma infraestrutura adequada, por procedimentos administrativos, pela capacitação docente, pela avaliação e atualização constantes, formação profissional e crítica, produção e avanço do conhecimento, transformação social, valorização da Pesquisa e da Extensão.

Toda instituição de Ensino é gerida pela chamada e conhecida Gestão escolar que, por sua vez, é composta por duas subdivisões chamadas de área pedagógica e área administrativa. A primeira com caráter norteador, pois está voltada diretamente ao objetivo-fim da instituição 
de Ensino. E a segunda apresenta-se como o apoio à primeira. Pois, é através da área administrativa que várias ações serão concretizadas em atendimento a demanda educacional.

O termo Gestão é definido como:

um processo que permite o desenvolvimento de atividades com eficiência e eficácia, a tomada de decisões com respeito às ações que se fizerem necessárias, a escolha e verificação da melhor forma de executá-las (RUMBLE, 2003, p. 15).

Entende-se, conforme tal visão, que existe a necessidade do labor agregado por parte de todos os envolvidos na Gestão escolar. E que seja articulada a concepção de complemento e reciprocidade entre as áreas pedagógica e administrativa com a intenção de obtenção da almejada qualidade do Ensino.

Conforme Pereira (2012), especialistas em educação necessitam deter formação e conhecimentos práticos que englobem conhecimentos cunho pedagógico e administrativo.

Concorda-se quando autores defendem a ideia de que não é simplesmente com a boa atuação da área pedagógica que as instituições de Ensino terão êxito. Seguindo esses passos, é de fácil entendimento, estas não poderão ser consideradas como autossuficientes, ou seja, o apoio administrativo se faz necessário e complementar as ações direcionadas ao bom funcionamento da Gestão pedagógica.

A direção da escola tem atribuições pedagógicas e administrativas próprias, e entre as mais importantes estão organização, administração e gestão do processo de tomadas de decisões por meio de práticas participativas e a execução das decisões tomadas. Em geral, ela atua mais diretamente nos aspectos administrativos, delegando os aspectos pedagógico-curriculares à coordenação pedagógica (ou outra designação equivalente ao trabalho de pedagogo escolar) (LIBÂNEO, 2008, p. 270).

Nota-se que as ações administrativas também apontam para o todo educacional. Em outras palavras, é por meio delas que os processos e práticas educacionais complementares tomam força. Porém, no dia a dia, não é sempre que esse apoio é entendido de maneira justa.

Não se pode diminuir a importância das discussões de temas vinculados ao administrativo, ou mesmo as emergências do cotidiano, uma vez que fazem parte e se inserem como elementos de um projeto pedagógico mais amplo; mas faz-se necessário reposicionar e resgatar os objetivos das reuniões; qualquer discussão deveria voltar-se para a reflexão sobre a ação de maneira ampla, não comportando reuniões comumente divididas em três partes: 0 início, com avisos gerais; num segundo momento, discussão sobre os problemas e dificuldades do dia-a-dia; e, finalmente, análise das questões pedagógicas (TORRES, 2003, p. 47). 
O alcance dos objetivos e execução dos processos e práticas educacionais só terão o devido êxito com a presença do Gestor principal da instituição de Ensino, que pode ser chamado de Diretor, Diretor geral ou Gestor. Enfim, independente de qual nomenclatura será usada para identificá-lo, seu papel é bem claro, através dele ocorre o planejamento e todas as ações de execução de procedimentos, práticas, tarefas, surtirão o efeito pretendido. Ele também contará com o apoio literal de todos os indivíduos (e também da comunidade externa), em outras palavras, o esforço coletivo de todos os envolvidos no objetivo de alcançar a um modelo educativo de qualidade.

São essas algumas funções do Gestor escolar: supervisionar práticas pedagógicas e administrativas; gerar integração entre a instituição escolar e a comunidade; conhecer as leis educacionais e criar maneiras para o fortalecimento as equipes de trabalho (LIBÂNEO, 2004).

Nota-se o quanto é importante considerar as ações de esforço coletivo em razão do desenvolvimento e aplicação do planejamento e práticas decorrentes das demandas impostas à Gestão escolar, tanto demandas oriundas do público interno, quanto externo ao ambiente educacional. O esforço coletivo, como mencionado acima, envolve diversos personagens e, segundo Maranhão (2014), trata-se de um grupo formado por vários blocos da comunidade escolar interna e externa (pais, alunos, professores e demais servidores), em que, através da participação, é possível auxiliar e agregar sobre as decisões que envolvem a instituição de Ensino nos âmbitos administrativo, político-pedagógico e financeiro.

Concorda-se que a participação das comunidades interna e externa juntamente à escola tende a fortalecer os laços e, em consequência, o planejamento, as ações e as futuras adequações necessárias para edificação de uma unidade escolar democrática e de qualidade que refletirá numa sociedade mais adequada aos profissionais e cidadãos que por ali um dia estiverem. A Gestão escolar é um sistema, no qual todas as personagens, suas funções e tarefas tem o poder de intervir de maneira muito significativa no resultado almejado pela instituição de Ensino, no caso, ofertar Educação de qualidade.

\section{Considerações finais}

A partir da reflexão exposta no decorrer desta pesquisa, fica evidente que, os termos abordados necessitam de maior aprofundamento. Que as informações aqui apresentadas não suprem de maneira total todas as nuances que envolvem a Gestão escolar, a tríade Ensino, Pesquisa e Extensão, bem como, o Ensino superior, o esforço coletivo e as personagens que ali se encontram, uma vez que seria impossível retratá-los de forma literal em poucas laudas. 
O intuito deste artigo, como mencionado no início, é descrever aspectos dos temas supracitados, para que, assim, fossem levantados questionamentos que culminassem em novos e mais aprofundados estudos.

O bom desenvolvimento e prática da Gestão escolar propiciará consequência para as ações voltadas ao todo institucional. E, esse olhar macro, refletirá de maneira positiva em cada área planejada e desenvolvida. A escola é um sistema no qual cada atitude e decisão refletirá nas demais áreas. Um exemplo claro disso, quase nunca levado em consideração, já imaginou uma escola sem energia elétrica, sem água, sem carteiras, sem um ambiente adequado para atuação dos profissionais envolvidos? Isso demonstra que dentro de uma instituição escolar todos têm sua devida importância (desde os serviços referentes a limpeza, passando pela manutenção dos ambientes, compra de equipamentos, aplicação de aulas e setores onde são tomadas as decisões de planejamento, entre outros), por menor que sejam consideradas as tarefas que realizam. Essa é a ideia do todo institucional, um complementa o trabalho do outro para que o objetivo maior seja alcançado.

Direcionando de forma mais específica o raciocínio ao tema principal deste estudo, é através da atenção globalizada atribuída ao um bom planejamento da Gestão escolar do Ensino superior e ao esforço coletivo das personagens envolvidas que o desenvolvimento da tríade Ensino, Pesquisa e Extensão terá possibilidade de ofertar, de forma sólida e justa, o conhecimento aos indivíduos, no caso aos alunos e à sociedade.

\section{REFERÊNCIAS}

BRASIL. Constituição (1988). Constituição da República Federativa do Brasil. Brasília, DF: Senado, 1988.

BRASIL. Lei n. 9.394, de 20 de dezembro de 1996. Lei de Diretrizes e Bases da Educação Nacional. Diário Oficial da União: Seção 1, Brasília, DF, n. 248, p. 27833, 23 dez. 1996. PL $1258 / 1988$

CAVALCANTE, J. F. Educação superior: conceitos, definições e classificações. Brasília: Instituto Nacional de Estudos e Pesquisas Educacionais, 2000.

CHIAVENATO, I. Introdução geral a teoria geral da administração. 7. ed. Rio de Janeiro: Campus, 2003.

DICIO. Dicionário Online de Português. Disponível em: https://www.dicio.com.br/. Acesso em: 01 jun. 2020.

FREIRE, P. Pedagogia da autonomia: saberes necessários à prática educativa. Rio de Janeiro: Paz e Terra, 1996. 
FÁVERO, M. L. A. A universidade brasileira em busca de sua identidade. Rio de Janeiro: Vozes, 1997.

LIBÂNEO, J. C. Organização e gestão da escola: teoria e prática. 4. ed. Goiânia: Alternativa, 2001.

LIBÂNEO, J. C. Organização e gestão da escola: teoria e prática. 5. ed. Goiânia, Alternativa, 2004.

LIBÂNEO, J. C. Organização e gestão da escola: teoria e prática. 5. ed. Revista e ampliada. Goiânia: MF Livros, 2008.

LÜCK, H. Dimensões de gestão escolar e suas competências. Curitiba: Positivo, 2009.

MACIEL, A. S. O princípio da indissociabilidade entre ensino, pesquisa e extensão: um balanço do período 1988-2008. 2010. 195 f. Tese (Doutorado em Educação) - Universidade Metodista de Piracicaba, Piracicaba, SP, 2010.

LAKATOS, E. M.; MARCONI, M. A. Metodologia do trabalho científico: procedimentos básicos, pesquisa bibliográfica, projeto e relatório, publicações e trabalhos científicos. 3. ed. São Paulo: Atlas, 1990.

MARTINS, J. Administração escolar: uma abordagem administrativa em educação. 2. ed. São Paulo: Editora Atlas, 1999.

MARANHÃO. Lei n. 104/2014. Projeto de Lei que cria o Plano Estadual de Educação. São Luís: PEE, 2014.

MOACYR, P. A instrução e o império. Subsídios para a história da educação no Brasil: 1854-1889. São Paulo: Companhia Editora Nacional, 1937.

MOITA, F. M. G. S. C; ANDRADE, F. C. B. Ensino-pesquisa-extensão: um exercício de indissolubilidade na pós-graduação. Revista Brasileira de Educação, Rio de Janeiro, v. 14, n. 41, p. 269-280. ISSN 1809-449X. 2009. DOI: https://doi.org/10.1590/S1413-

24782009000200006

NEVES, C. E. B. A estrutura do ensino superior no Brasil. In: SOARES, M. S. A. (Org.). A educação superior no Brasil. Brasília: CAPES, 2002.

PEREIRA, S. M. Impasses e perspectivas para a democratização da gestão escolar: os especialistas técnicos em questão. Currículo sem Fronteiras, v. 12, n. 1, p. 244-268, jan./abr. 2012.

FORPROEX. Política de Extensão Universitária. Fórum de Pró-Reitores de Extensão das Universidades Públicas Brasileiras (FORPROEX). João Pessoa, PB, 2009.

RAYS, O. A. Ensino-Pesquisa-Extensão: notas para pensar a indissociabilidade. Revista Cadernos de Educação Especial, Santa Maria, n. 21, 2003. DOI:

http://dx.doi.org/10.5902/1984686X 
RODRIGUES, G. M. Desafios da gestão universitária contemporânea. Porto Alegre: Artmed, 2011.

ROSSATO, E. A expansão do ensino superior no Brasil: do domínio público à privatização. Passo Fundo: Universidade de Passo Fundo, 2006.

RUMBLE, G. A gestão dos sistemas de ensino a distância. Brasília: Unesco, 2003.

SANDER, B. Administração da educação no Brasil: genealogia do conhecimento. Brasília: Liber Livro, 2007.

SANTOS, C. R. A gestão educacional e escolar para a modernidade. São Paulo: Cencage Learning, 2008.

SANTOS, T. M. Noções de administração escolar. São Paulo: Companhia Editora nacional, 1996.

SILVA, N. M. N. P. De missão à jornada: o caminho da educação. Andirá: Ed. Godoy, 2007.

SOARES, J. F. Melhora do desempenho cognitivo dos alunos do ensino fundamental. Cadernos de Pesquisa, São Paulo, v. 37, n. 130, p. 135-160, jan./abr. 2007. DOI: https://doi.org/10.1590/S0100-15742007000100007

TORRES, C. A. Teoria crítica e sociologia política da educação. In: TORRES, C. A. (Org.). Teoria crítica e sociologia política da educação. São Paulo: Cortez: Instituto Paulo Freire, 2003.

\section{Como referenciar este artigo}

MONTEIRO, J. A. Aspectos da gestão escolar e da tríade ensino, pesquisa e extensão. Revista on line de Política e Gestão Educacional, Araraquara, v. 25, n. 1, p. 52-67, jan./abr. 2021. e-ISSN:1519-9029. DOI: https://doi.org/10.22633/rpge.v25i1.13913

Submetido em: 09/05/2020

Revisões requeridas: 28/07/2020

Aceito em: 10/09/2020

Publicado em: 02/01/2021 